\title{
O lastro educacionalizante da experiência contemporânea:
} problematizações

\author{
Elisa Vieira* \\ Julio Groppa Aquino**
}

\section{Resumo}

A título de inscrição no debate acerca daquilo que alguns autores têm denominado pedagogização ou educacionalização do social, o presente trabalho propõe-se a abordar a performatividade discursiva em torno da intensificação de práticas educacionais para além de sua versão formal, compreendendo esse movimento como um processo sócio-histórico de inegável impacto na gestão de condutas humanas e, por extensão, na conformação de cidadãos educáveis. A análise, cuja fundamentação teóricometodológica dialoga estreitamente com o pensamento de Michel Foucault, empreende uma contextualização cartográfica das iniciativas teóricas e práticas em torno da educação não escolar, tendo como base um conjunto de textos publicados em dez periódicos nacionais de ampla circulação na área da educação durante as últimas duas décadas (1995-2014). Tal material empírico, aqui entendido como locus de circulação e validação do que se tem produzido nas práticas pedagógicas não formais em tempos recentes, oferece ocasião privilegiada para a problematização das novas feições que o horizonte educacional vem assumindo. Trata-se, assim, de compor um inventário de tematizações, teorizações e métodos que se afirmam a reboque de práticas educacionais situadas fora do escopo clássico da instituição escolar e que, segundo nossa hipótese, portariam um proeminente acento educacionalizante a investir os modos de vida contemporâneos.

Palavras-chave: Educação Extraescolar. Revistas de Educação. Foucault, Michel.

\footnotetext{
* Doutorado em Educação na Universidade de São Paulo (USP).

*** Doutorado em Psicologia Escolar e do Desenvolvimento Humano pela Universidade de São Paulo (USP). Professor da Faculdade de Educação da Universidade de São Paulo (USP).
} 


\section{Introdução}

Se é possível dizer que educação é palavra de primeira ordem entre as preocupações de nosso tempo, é igualmente possível afirmar que os novos contextos a ela relacionados ultrapassam sobremaneira o âmbito escolar. Segundo nossa hipótese, a intensificação das práticas educacionais para além das fronteiras da instituição escolar poderia, grosso modo, ser disposta em termos de um movimento consubstanciado pela rotação de dois eixos complementares: disjunção e dispersão (AQUINO, 2012). O primeiro deles refere-se a uma polivalência de funções derivadas de demandas das mais variadas instâncias sociais que hoje são atribuídas à escola e aos profissionais a ela associados, funções estas responsáveis por saturar o escopo de atuação daquela instituição, redundando num efeito disjuntivo entre os clamores sociais do presente e as respostas institucionais, geralmente conotadas como insuficientes, a eles oferecidas. No segundo eixo situar-se-ia o fenômeno caracterizado por um “espraiamento sem precedentes de práticas de teor pedagogizante, não mais circunscritas ao espaço escolar" (AQUINO, 2012, p. 148). De um lado e de outro, o que se constata é uma pronunciada dilatação das práticas educacionais, seja no sentido de incorporar novas preocupações aos seus domínios, seja na investida tentacular de multiplicação de suas formas rumo a outros espaços e outros contextos fáticos.

É precisamente ao eixo da dispersão que se dedica a proposta argumentativa em tela no presente texto. Segundo o diagnóstico de uma série de pesquisadores, facetas específicas desse mesmo movimento dilatador têm recebido tratamentos semelhantes, seja em termos de sociedade de aprendizagem (NOGUERA-RAMIREZ, 2009), de pedagogização (BERNSTEIN, 2003) ou de educacionalização (DEAPEPE, 2012). Nessa direção, tendo em vista o espaço alargado que hoje tem sido dedicado às práticas educativas não escolares, parece-nos coerente defini-lo como um movimento de expansionismo pedagógico cujo efeito nuclear seria o de converter exponencialmente as relações entre as pessoas e suas experiências cotidianas em alvos passíveis de conhecimento e de intervenção pedagógica.

$\mathrm{Na}$ esteira de tal movimento, passa-se a atribuir um caráter educativo subjacente a essas relações e experiências, investindo-as de determinada intencionalidade educativa. Se supusermos, porém, que não há objetos a priori, mas objetivações ininterruptas, somos levados a interrogar as relações de poder-saber que aí se forjam, entendendo que um investimento dessa monta acaba por oportunizar focos de experiência (FOUCAULT, 2010a), os quais passam a compor os modos de 
governo das populações - modos, portanto, impregnados de um proeminente substrato educacionalizante.

No que concerne às justificativas para uma problematização dessa natureza, é de se prever que elas posssam chocar-se com a alegação de que o espraiamento do intento educacional seria indubitavelmente favorável ao progresso, à democratização e ao desenvolvimento social. Contudo, como bem afirmam Popkewitz, Olsson e Petersson (2009), é preciso historicizar o senso comum - no caso, aquele que defende o expansionismo pedagógico e o espraiamento das práticas desse timbre como bens inquestionáveis - e diagnosticar uma série de cerceamentos em curso, uma vez que os princípios de uma sociedade organizada em torno de tal mote são solidários a modos implacáveis de governamento, constituindo efeitos de poder naturalizados e, portanto, sem contestação. Modos e efeitos nem execráveis, nem desejáveis a priori, vale lembrar, mas indubitavelmente presentes entre os vetores que nos subjetivam dia a dia, mesmo - e sobretudo - quando deles não nos apercebemos.

Daí a justificação do intento geral deste artigo, diretamente inspirado no pensamento de Michel Foucault: interrogar aquilo que temos nos tornado, buscando traçar os jogos performativos em que nos encontramos enredados subjetivamente. Tal perspectiva de compreensão da paisagem sociocultural contemporânea pode ainda ser definida nos seguintes dizeres do pensador francês: "a análise crítica de nosso mundo tornou-se algo cada vez mais importante. Talvez, o mais evidente dos problemas filosóficos seja a questão do tempo presente e daquilo que somos neste exato momento" (FOUCAULT, 2010b, p. 283).

Como objetivo específico, trata-se aqui de empreender uma contextualização cartográfica de iniciativas teóricas e práticas em torno da educação não escolar, a fim de dar a ver algumas das feições que o horizonte educacional tem assumindo na contemporaneidade. Tal propósito, aliás, está alinhado a um interesse investigativo mais amplo que dispara investigações por nós já efetuadas, algumas delas em curso (AQUINO, 2012; VIEIRA, 2012).

Para a presente ocasião, elegemos como matéria empírica um conjunto de textos publicados em dez periódicos nacionais de ampla circulação na área da educação durante as últimas duas décadas (1995-2014). No intuito de apresentar os resultados da pesquisa, o artigo está organizado segundo dois momentos analíticos: o primeiro, de cunho mais quantitativo, visa oferecer um quadro geral do que foi possível subtrair do material selecionado, destacando movimentos, tendências, predominâncias quanto às iniciativas educacionais de timbre não escolar; o segundo oferece uma análise mais vertical da questão em foco, a partir de quatro artigos escolhidos com base nos achados apresentados anteriormente. Trata-se, nesse segundo momento, de discutir determinadas teorizações, justificativas e 
proposições que parecem nortear o discurso da educação não escolar. Ainda, a fim de sustentar a análise, apresentamos inicialmente as escolhas e os procedimentos utilizados no endereçamento às fontes. Ao final, tecemos uma apreciação crítica dos saldos analíticos.

\section{Composição e análise do arquivo}

A fim de levar a cabo a problematização ora anunciada, tomamos a produção acadêmicocientífica nacional como locus analítico, por entendê-la como um nicho discursivo suficientemente sólido e abrangente para evidenciar aquilo que vem se operando no campo educacional em tempos recentes. Tal fonte empírica, por um lado, pode ser pensada como um dos suportes concretos de reconhecimento e validação do estatuto pedagógico das relações educativas internas e/ou externas à instituição escolar; por outro, trata-se de um significativo locus de reverberação daquilo que se passa no campo das práticas concretas, uma vez que permite circular apropriações de ensejo teorizante dessas mesmas práticas. Tais características são indissociáveis e, juntas, compõem o caráter performativo do material em análise.

Nesse sentido, vale dizer, nossa eleição não está pautada na representatividade dos dados, ou seja, em uma relação todo/parte supostamente unívoca entre discursos e realidades, de tal modo que aqueles fossem mostra fidedigna destas. É justamente por situar o arquivo no próprio interior de uma empiria que a ele conferimos o sentido de uma dentre tantas práticas próprias de um tempo, em consonância com o modo como Arlette Farge (2009, p. 35) o compreende: "Talvez o arquivo não diga a verdade, mas ele diz da verdade, tal como o entendia Michel Foucault [...]. O real do arquivo torna-se não apenas vestígio, mas também ordenação de figuras da realidade; e o arquivo sempre mantém infinitas relações com o real”".

Com isso queremos afirmar que, se não há pretensão de representar algo que corresponderia de forma direta a uma realidade factual, há, entretanto, a tentativa deliberada de tomar um conjunto discursivo específico como ocasião de reflexão e tensionamento do que ele próprio opera em sua condição de prática efetiva.

Para a constituição do arquivo, foram selecionados os seguintes periódicos: Cadernos de Pesquisa, Educação \& Realidade, Educação \& Sociedade, Educação e Pesquisa, Educação em Questão, Educação em Revista, Educar em Revista, Perspectiva, Revista Brasileira de Educação e Revista Brasileira de Estudos Pedagógicos. Aí estão incluídas publicações classificadas nas categorias A1, A2 e B1 pelo sistema Qualis Periódicos da CAPES, segundo sua última avaliação, em 2013. 
Os dez periódicos estão alocados em instituições distintas distribuídas pelos estados brasileiros. Três deles estão situados na Região Sul, especificamente na Universidade Federal do Rio Grande do Sul - UFGRS (Educação \& Realidade), na Universidade Federal do Paraná - UFPR (Educar em Revista) e na Universidade Federal de Santa Catarina - UFSC (Perspectiva). Já na Região Sudeste, a seleção contou com cinco periódicos, editados pelas seguintes instituições: Fundação Carlos Chagas FCC (Cadernos de Pesquisa); Centro de Estudos Educação e Sociedade, da Universidade Estadual de Campinas (Educação \& Sociedade); Universidade de São Paulo - USP (Educação \& Pesquisa); Universidade Federal de Minas Gerais - UFMG (Educação em Revista); e Associação Nacional de Pós-Graduação e Pesquisa em Educação - ANPEd (Revista Brasileira de Educação). Um dos periódicos tem sua sede na Região Centro-Oeste, em Brasília, estando a cargo do Instituto Nacional de Estudos e Pesquisas Educacionais Anísio Teixeira - Inep (Revista Brasileira de Estudos Pedagógicos). Por fim, o décimo periódico é proveniente da Região Nordeste, publicado pela Universidade Federal do Rio Grande do Norte - UFRN (Educação em Questão).

No Quadro 1 são dispostos os dados gerais de tais publicações e a distribuição dos textos selecionados, por periódico.

Quadro 1 - Caracterização dos periódicos analisados e quantidade de artigos selecionados por publicação

\begin{tabular}{|c|c|c|c|c|c|c|c|}
\hline \multirow[b]{2}{*}{ Periódico } & \multirow[b]{2}{*}{ Entidade responsável } & \multirow[b]{2}{*}{ Qualis } & \multirow{2}{*}{ Fundação } & \multirow{2}{*}{$\begin{array}{c}\text { Fascículos } \\
\text { de } 1995 \text { a } \\
2014 \\
\end{array}$} & \multicolumn{3}{|c|}{ Artigos selecionados } \\
\hline & & & & & \begin{tabular}{|c|} 
Autores \\
nacionais
\end{tabular} & \begin{tabular}{|c|} 
Autores \\
estrangeiros
\end{tabular} & Total \\
\hline Cadernos de Pesquisa & $\begin{array}{l}\text { Fundação Carlos Chagas } \\
\text { (FCC) }\end{array}$ & A1 & 1971 & 63 & 11 & 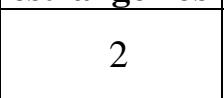 & 13 \\
\hline $\begin{array}{l}\text { Educação \& } \\
\text { Realidade }\end{array}$ & $\begin{array}{c}\text { Faculdade de Educação da } \\
\text { UFRGS }\end{array}$ & A1 & 1976 & 48 & 12 & 3 & 15 \\
\hline $\begin{array}{l}\text { Educação \& } \\
\text { Sociedade }\end{array}$ & $\begin{array}{l}\text { Centro de Estudos Educação e } \\
\text { Sociedade (CEDES) }\end{array}$ & A1 & 1978 & 80 & 5 & 3 & 8 \\
\hline Educação e Pesquisa & $\begin{array}{l}\text { Faculdade de Educação da } \\
\text { USP }\end{array}$ & A1 & 1975 & 54 & 8 & 2 & 10 \\
\hline Educação em Questão & Centro de Educação da UFRN & A2 & 1987 & 39 & 12 & 2 & 14 \\
\hline Educação em Revista & $\begin{array}{l}\text { Faculdade de Educação da } \\
\text { UFMG }\end{array}$ & A1 & 1985 & 50 & 35 & 2 & 37 \\
\hline Educar em Revista & Setor de Educação da UFPR & A1 & 1977 & 53 & 29 & 4 & 33 \\
\hline Perspectiva & $\begin{array}{l}\text { Centro de Ciências da } \\
\text { Educação da UFSC }\end{array}$ & $\mathrm{A} 2$ & 1983 & 48 & 12 & 7 & 19 \\
\hline $\begin{array}{c}\text { Revista Brasileira de } \\
\text { Educação }\end{array}$ & $\begin{array}{c}\text { Associação Nacional de Pós- } \\
\text { Graduação e Pesquisa em } \\
\text { Educação (ANPED) }\end{array}$ & A1 & 1995 & 60 & 26 & 3 & 29 \\
\hline $\begin{array}{l}\text { Revista Brasileira de } \\
\text { Estudos Pedagógicos }\end{array}$ & $\begin{array}{l}\text { Instituto Nacional de Estudos e } \\
\text { Pesquisas Educacionais Anísio } \\
\text { Teixeira (INEP) }\end{array}$ & B1 & 1944 & 60 & 11 & 0 & 11 \\
\hline \multicolumn{4}{|c|}{ (2) } & 555 & 161 & 28 & 189 \\
\hline
\end{tabular}

Fonte: Elaborado pelos autores (2016). 
Tal como se pode observar, foram selecionados ao todo 189 artigos. Destes, 28 são produções ligadas exclusivamente a autores estrangeiros, tendo sido contabilizados apenas a título de indicação. Entre os autores estrangeiros, a predominância foi de pesquisadores portugueses, o que talvez se justifique não apenas pelo fato de o idioma ser o mesmo, mas também por se concentrarem naquele país importantes núcleos dedicados a temas afins à educação não escolar. Para os propósitos deste trabalho, a análise considerou a produção vinculada apenas a autores brasileiros, o que equivaleu a 161 textos e 246 autores.

Não houve recorrência significativa de pesquisadores que assinaram os artigos, mas ainda assim é válido mencionar aqueles que se repetiram, compondo a autoria de mais de um texto afim ao tema da educação não escolar. As pesquisadoras Marília Pontes Sposito (USP), Sonia Maria Rummert (Universidade Federal Fluminense - UFF) e Soraia Napoleão Freitas (Universidade Federal de Santa Maria - UFSM) destacaram-se, cada uma, pela autoria de três dos artigos selecionados. Outro grupo de autores foi referenciado, cada um deles, em dois dos textos que compuseram nosso arquivo: Andreia Aparecida Marin (UFPR), Antônio Cabral Neto (UFRN), Carin Klein (Rede Municipal de Canoas), Carlos Frederico Bernardo Loureiro (Universidade Federal do Rio de Janeiro), Celso de Rui Beisiegel (USP), Dagmar E. Estermann Meyer (UFRGS), Danilo R. Streck (Universidade do Vale do Rio dos Sinos), Elionaldo Fernandes Julião (UFF), Francisco Dutra de Macedo Filho (UFRN), Geraldo Magela Pereira Leão (UFMG), Jane Paiva (Universidade do Estado do Rio de Janeiro), Leodi Conceição Meireles Ortiz (UFSM), Maria Amélia G. G. Giovanetti (UFMG), Marlene Ribeiro (UFRGS), Mary Julia Martins Dietzsch (USP), Nilton Bueno Fischer (UFRGS), Rodrigo Manoel Dias da Silva (Universidade Federal da Fronteira Sul), Rosália Duarte (Pontifícia Universidade Católica do Rio de Janeiro), Rosângela Soares (UFRGS) e Sinara Pollom Zardo (UFSM).

Entre os artigos selecionados, a distribuição por periódico não se deu de maneira uniforme: a publicação que compareceu com maior quantidade de textos relativos à educação não escolar foi Educação em Revista (22\%), seguida por Educar em Revista (18\%) e Revista Brasileira de Educação (16\%). Já o periódico que apresentou menor ocorrência do tema ao longo do período pesquisado foi Educação \& Sociedade (3\%), informação digna de atenção, sobretudo devido ao fato de ser essa a publicação com maior número de fascículos veiculados no período. Outro periódico que também teve presença consideravelmente tímida foi Educação \& Pesquisa (5\%).

Tais dados, embora não ofereçam relevância ou precisão para a análise da questão ora mobilizada, permitem algumas asserções. Em primeiro lugar, a discrepância entre as quantidades de 
artigos encontradas em cada periódico dá margem à hipótese de que haveria diferenças entre as respectivas linhas editoriais. Tal suposição requereria um estudo mais aprofundado sobre as distintas modulações e os interesses particulares de tais publicações, o que não será levado a cabo aqui. É possível conjecturar, contudo, que a abertura que supomos existir no interior do campo pedagógico para as problemáticas não escolares seja mais sensível em alguns nichos editoriais específicos.

De todo modo, vale acrescentar uma informação complementar, relativa à filiação institucional dos autores responsáveis pelos artigos selecionados. Entre as instituições envolvidas, as cinco mais recorrentes foram: Universidade Federal de Minas Gerais (UFMG), Universidade Federal do Rio Grande do Sul (UFRGS), Universidade de São Paulo (USP) - cada uma das três representada por 22 autores (9\%) -, Universidade Federal do Paraná (UFPR) e Universidade Federal de Santa Maria (UFSM) - ambas representadas por 14 autores (5,7\%). Sabe-se que há tendências próprias de produção acadêmica e concentração de publicações em determinadas regiões do país (sobretudo no eixo SulSudeste), o que é reiterado pelos montantes encontrados. É de se notar, contudo, que algumas informações parecem se repetir: a UFMG, por exemplo, destaca-se tanto como instituição de concentração dos autores contabilizados, quanto como entidade mantenedora da Educação em Revista, periódico com maior ocorrência de textos. Resultado semelhante encontramos no caso da UFPR e do periódico Educar em Revista.

Quanto às características temporais da produção, optamos, para uma melhor visualização, pela divisão do período considerado em quatro quinquênios, conforme Quadro 2, a seguir.

Quadro 2 - Distribuição dos artigos nacionais selecionados por quinquênio

\begin{tabular}{|c|c|}
\hline Período & Quantidade de artigos \\
\hline $1995-1999$ & 16 \\
\hline $2000-2004$ & 31 \\
\hline $2005-2009$ & 59 \\
\hline $2010-2014$ & 55 \\
\hline
\end{tabular}

Fonte: Elaborado pelos autores (2016).

Vê-se aí um incremento substancial da produção acadêmica sobre educação não escolar ao longo das últimas duas décadas. Mais uma vez, a informação deve ser relativizada, devido ao concomitante aumento do próprio volume de fascículos editados anualmente por cada periódico. No entanto, ainda assim é possível supor que o interesse pela temática tem crescido gradualmente, já que o 
aumento supera a margem de $340 \%$, enquanto nenhuma das revistas estudadas teve aumento maior que $200 \%$ em seus fascículos publicados.

Partindo do pressuposto de que tais dados quantitativos parecem corroborar a hipótese de uma atenção crescente para com questões exógenas ao meio escolar, vejamos agora que forma esse movimento assume em termos de conteúdos propriamente. Em primeiro lugar, dimensionamos o arquivo conforme a natureza dos argumentos que sustentam os textos veiculados. A esse respeito, foi possível identificar que $64 \%$ dos artigos são declaradamente favoráveis e propositivos em relação à ideia geral de práticas educativas não escolares, ao passo que apenas 14\% manifestaram-se de modo crítico quanto a isso; os $22 \%$ restantes não apresentaram um posicionamento suficientemente explícito para que pudéssemos enquadrá-los em um dos dois polos aqui mencionados. Além disso, mais da metade do material é composta por estudos de casos empíricos, fazendo referência a projetos e práticas já em curso.

Até aqui, pudemos sintetizar algumas linhas gerais: a educação não escolar tem sido alvo de pronunciado interesse por parte dos pesquisadores brasileiros da área da educação; tais pesquisadores, em sua maioria, posicionam-se favoráveis a iniciativas educacionais efetuadas fora dos limites escolares; há no país uma quantidade significativa de práticas nessa direção que atualmente são alvo de investida acadêmica.

Dando prosseguimento à cartografia almejada, detemo-nos, a seguir, nos temas mobilizados pelos textos selecionados. Para tanto, façamos um recuo a fim de explicitar o tratamento que dispensamos ao arquivo, na intenção de compreender sua contextualização temática.

\section{Categorizando a dispersão}

A triagem e a seleção do material de análise consistiram primeiramente na imersão nos títulos, resumos e palavras-chave de todos os artigos publicados pelos dez periódicos entre 1995 e 2014. A opção por tal estratégia - mais morosa e precisa do que a busca por descritores - deu-se sobretudo devido à natureza de nosso intento investigativo na presente empreitada. Como se tratava justamente de inventariar as formas de manifestação da educação não escolar ao longo do período, bem como os diversos campos e temas por elas investidos, não era possível traçar de antemão uma lista de termos a serem rastreados. Ademais, a própria noção de educação não escolar é aqui assumida como uma classificação analítica a posteriori, ou seja, como uma designação que atribuímos a determinadas práticas, teorizações e proposições a partir de uma definição específica elaborada conforme nossa 
hipótese de pesquisa. Quer isso dizer que muitas vezes os artigos que nos interessavam não traziam consigo uma autodenominação nesse sentido, cabendo a nós atribuir-lhes tal identificação. Assim, tampouco o termo educação não escolar - ou não formal - era adequado para uma busca na massa discursiva informe de que dispúnhamos.

Desprovidas de classificações apriorísticas, portanto, as categorias de organização do material emanaram de seu próprio manuseio. Por isso, cumpre-nos ressaltar que os tópicos selecionados não correspondem à porção integral de seu aparecimento nos periódicos; é o caso da educação ambiental, uma das temáticas mais recorrentes no arquivo, como se verá adiante. Os artigos a esse respeito muitas vezes restringiam seu alcance ao contexto escolar, discutindo ou propondo iniciativas relativas à questão ambiental aplicadas a disciplinas e atividades escolares. Tais textos, obviamente, não foram incluídos no material de análise, pois, embora estivessem alinhados com temas afins aos que nos interessavam, não cumpriam o requisito fundamental de se centrarem explicitamente fora do contexto escolar.

Tendo tal distinção em mente, os artigos selecionados foram classificados conforme 22 categorias temáticas, de modo a possibilitar um panorama abrangente das subáreas correlatas, por meio do qual desponta um retrato extensivo da diversidade de temáticas que têm sido investidas atualmente por iniciativas educacionais não escolares. Tais categorias por vezes aparecem combinadas em um mesmo texto (por exemplo, quando um artigo discorre sobre a função educativa de um programa televisivo direcionado a crianças, ele está classificado como educação e mídia e, concomitantemente, como educação e infância). A seguir, listamos as 22 categorias elencadas, bem como uma breve descrição do que cada uma delas compreendeu:

- Educação e infância: compreende processos educativos diretamente voltados para o público infantil, englobando projetos urbanos específicos, bem como aprendizagens em situações de brincadeira, em programas televisivos e em contextos como hospital, periferia, museu e cultura indígena;

- Educação e juventude: reflexões que têm nos jovens seu principal alvo de atenção, seja em relação a tópicos como sexualidade, ambiente virtual, mídia televisiva e projetos socioeducativos, seja em relação a dimensões educativas de experiências como escotismo e acampamento; 
- Educação de jovens e adultos: práticas educativas especificamente direcionadas ao público jovem e adulto, em geral subsumidas na modalidade (por vezes também escolar) da Educação de Jovens e Adultos (EJA) e relacionadas a preocupações laborais;

- Educação e velhice: refere-se a práticas de cunho educacional direcionadas especificamente ao público idoso;

- Educação e cidade: inclui estudos voltados à educação no contexto difuso das cidades e tópicos mais específicos relativos a aparatos urbanos (por exemplo, educação em parques); não contempla, entretanto, casos em que a questão social é alvo predominante do artigo, embora o contexto também seja urbano (por exemplo, projetos socioeducativos destinados ao público em situação de rua que não apresentam reflexão específica sobre a questão urbana);

- Educação no campo: artigos dedicados aos processos educativos que ocorrem em contexto campesino, seja em relação a aprendizagens ali possíveis de forma acidental, seja em relação a projetos intencionalmente educativos;

- Educação prisional: compreende a dimensão educativa presente em contexto carcerário, tanto no que se refere a processos incidentais, quanto no que se refere a programas de reinserção social e de promoção da leitura entre o público presidiário, envolvendo, ainda, questões de gênero;

- Educação em museus: inclui programas educacionais e materiais pedagógicos desenvolvidos para ambientes museológicos (sobretudo em relação a áreas como ciências e história), bem como outros processos educativos possíveis em tais contextos;

- Educação hospitalar: abrange iniciativas educativas alocadas em hospitais e enfermarias (em geral relativas ao que se denomina classes hospitalares), bem como processos educativos não intencionais que podem ocorrer em ambientes hospitalares;

- Educação e mídia: questões educacionais relativas a meios midiáticos (seja de modo intencional ou acidental, sejam práticas ocasionadas pela mídia, seja ainda uma educação voltada para a mídia), compreendendo televisão, imprensa, rádio e cinema;

- Educação e família: refere-se ao tema geral da educação ocorrida em contexto familiar, compreendendo tópicos como maternidade e práticas parentais, além de reflexões sobre a função educativa da família;

- Educação indígena: abarca os processos educativos que se passam no interior da cultura indígena, envolvendo transmissão intergeracional e reivindicações em torno do tema; 
- Educação e cultura: casos em que a reflexão central se dá em torno da função educativa da cultura, seja esta tomada em um sentido amplo ou em eixos específicos (por exemplo, cultura popular, cultura caipira, cultura musical); também abarca tópicos como multiculturalismo e afins;

- Educação e esporte: compreende os processos educativos possíveis de ocorrência em contextos esportivos, bem como a utilização de jogos e demais atividades esportivas como ocasião educativa;

- Educação e meio ambiente: inclui a questão geral da educação ambiental e tópicos mais específicos, como preservação animal, educação em zoológicos, sustentabilidade, consumo sustentável e agroecologia, além de textos sobre o estado da arte referente à temática;

- Educação e movimentos sociais: considera tanto a temática da educação que se passa no interior dos movimentos sociais organizados quanto as demandas educativas apresentadas por esses movimentos;

- Educação e assistência: trata da educação voltada a questões sociais (marginalidade, exclusão, pobreza, criminalidade), situação de rua, instituições de abrigo, ou seja, iniciativas educacionais voltadas a finalidades de assistência social;

- Educação e religião: inclui tanto a educação propriamente religiosa quanto as iniciativas educativas alocadas em contextos religiosos;

- Educação e saúde: práticas de teor educativo direcionadas à promoção da saúde, à conscientização e à prevenção de doenças, bem como tópicos específicos, como educação sexual e do corpo;

- Educação e tecnologia: compreende as relações entre educação e uso de Tecnologias da Informação e Comunicação (TIC), abrangendo temas como educação online, ambientes virtuais e inclusão digital;

- Educação e trabalho: textos que abordam tanto a função educativa do trabalho (e dos processos pedagógicos que se passam no contexto laboral) quanto iniciativas intencionais de cunho pedagógico voltadas a trabalhadores;

- Formação e atuação profissional: inclui casos que se debruçam sobre a formação de quadros profissionais específicos para exercício em educação não escolar, discutindo tanto a entrada desse campo de atuação nos currículos dos cursos de pedagogia e a ausência de formação própria para a função, quanto as competências necessárias a serem desenvolvidas. 
Se o esforço de categorização por nós levado a cabo decerto não logrou oferecer uma listagem sintética dos principais temas/contextos que permearam os artigos, isso também se deveu à intenção de mapear os achados pautando-nos mais pelo detalhe do que pela economia representativa. Nesse sentido, a ampla paleta de categorias identificadas acaba por ser, ela própria, evidência da dispersão de atribuições educacionalizantes aos mais diversos enquadres da organização societária contemporânea. Vejamos, no Gráfico 1, como tal dispersão se manifesta.

\section{Gráfico 1 - Ocorrência de categorias temáticas no arquivo (tendo por referência os 161 artigos)}

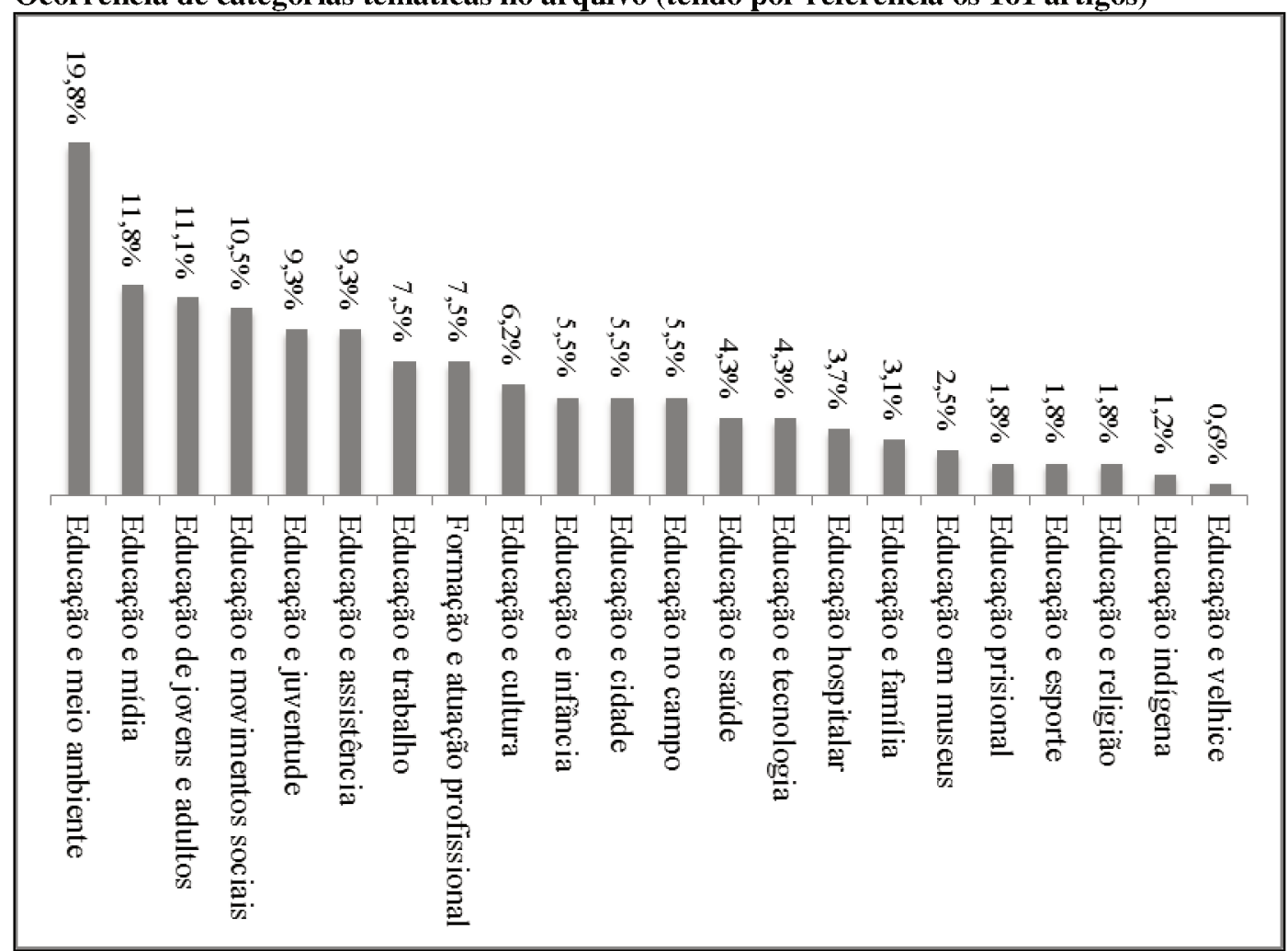

Fonte: Elaborado pelos autores (2016).

O tema educação e meio ambiente destacou-se significativamente nos artigos analisados (32 ocorrências), seguido por educação e mídia (19 ocorrências) e educação de jovens e adultos (18 ocorrências). A temática de menor predominância foi educação e velhice (apenas uma ocorrência).

Entre as categorias temáticas que listamos, há diferenças significativas quanto às características dos artigos. Se considerarmos, por exemplo, as três mais recorrentes, temos as seguintes configurações: dos textos que tiveram como foco educação e meio ambiente, apenas $9 \%$ declararam-se críticos em relação a práticas não escolares voltadas para a questão ambiental; já entre aqueles sobre educação $e$ mídia, tal percentual é de $42 \%$; por fim, apenas $5 \%$ dos artigos relativos à educação de jovens e adultos 
disseram-se críticos a esse respeito. Com isso é possível perceber que alguns nichos temáticos têm maior prevalência de adesão do que outros, talvez mais controversos entre os pesquisadores.

Outro aspecto que merece ser destacado é a distribuição temporal das categorias. Nos primeiros cinco anos analisados (1995-1999), somente 10 dos 22 temas foram tratados. Já no último quinquênio (2010-2014), de todos os temas encontrados, apenas um deles não esteve presente. Ou seja, podemos observar que houve uma inegável dispersão temática da questão educativa não escolar, indicando um aumento gradual de seus alvos de interesse.

Num segundo esforço de classificação, agora mais globalizante, foi possível agrupar as categorias iniciais em seções mais amplas, as quais acabaram por evidenciar nichos gerais de operação das iniciativas educacionais não escolares. Desta feita, podemos reconhecer que tais iniciativas se expandem rumo a outras temporalidades, a outras espacialidades e a outras questões socioculturais, para além de seu escopo tradicional, circunscrevendo um campo bastante diversificado de atuação. Daí os três seguintes agrupamentos:

- Educação na extensão da vida (educação e infância, educação e juventude, educação de jovens e adultos, educação e velhice);

- Educação na extensão dos espaços cotidianos (educação e mídia, educação e cidade, educação no campo, educação hospitalar, educação e família, educação em museus, educação prisional);

- Educação na extensão das questões socioculturais (educação e meio ambiente, educação e movimentos sociais, educação e assistência, educação e trabalho, educação e cultura, educação e saúde, educação e tecnologia, educação e esporte, educação e religião, educação indígena).

À parte, ainda, é preciso considerar o eixo formação e atuação profissional na educação não escolar, que, embora seja representado por apenas uma categoria, diz respeito a uma dimensão fundamental das questões em torno da educação não escolar, conforme discutiremos adiante.

Com base nessa segunda classificação, uma nova disposição dos dados se fez possível. Vejamos no Gráfico 2, que segue. 
Gráfico 2 - Ocorrência no arquivo das categorias temáticas agrupadas (tendo por referência os 161 artigos)

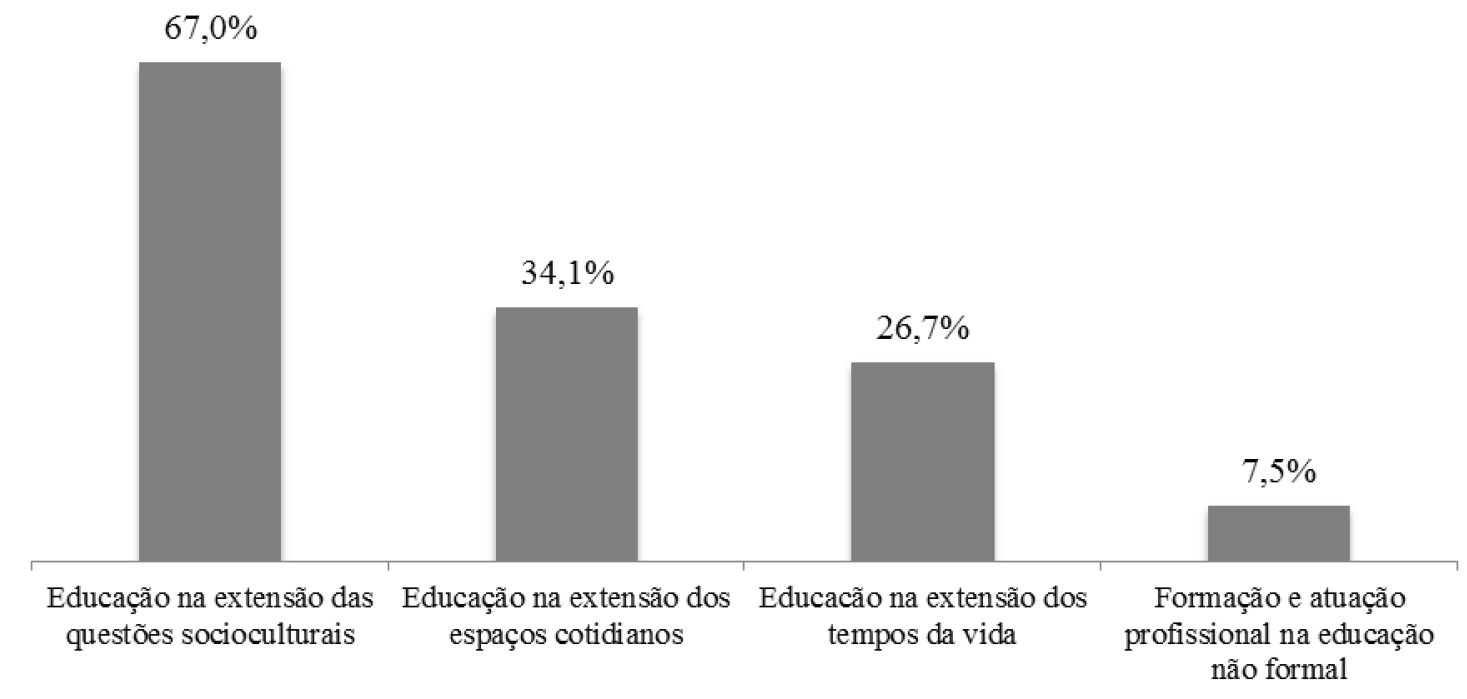

Fonte: Elaborado pelos autores (2016).

Temos aí disposto um quadro mais geral dos interesses educacionais para além da instituição escolar: eles têm alcance tanto em diversas problemáticas socioculturais quanto em espaços e tempos abrangentes da vida contemporânea, havendo incidência, ainda, de uma preocupação voltada para certo aparato formativo/profissional que sustente tal campo de atuação. Embora a concentração de textos varie entre os eixos, vale lembrar que eles muitas vezes aparecem concomitantemente, situação diante da qual nossa categorização deu destaque aos âmbitos que ocupavam primeiro plano de tematização em cada peça textual.

\section{Quatro casos da educação não escolar}

De posse dos dados até aqui apresentados, façamos agora uma incisão mais precisa no arquivo, à moda de breves estudos de caso. Para tanto, operaremos um segundo recorte no material selecionado a fim de eleger textos emblemáticos das tendências gerais encontradas. Quatro foram os artigos escolhidos, cada um deles situado em um dos quatro agrupamentos temáticos propostos anteriormente.

Agroecologia, consumo sustentável e aprendizado coletivo no Brasil (SANTOS; CHALUBMARTINS, 2012), publicado em Educação e Pesquisa, representa o eixo que denominamos educação na extensão das questões socioculturais e aborda o tema específico educação e meio ambiente. O texto parte da experiência empírica de um grupo de consumo coletivo de produtos agroecológicos para analisar as operações educativas em curso nas relações entre os indivíduos participantes. Nesse sentido, 
apresenta caráter propositivo, uma vez que defende a prática sobre a qual se debruça como alternativa viável e ressalta seu potencial educativo como fator positivo.

Tal como observamos em grande parte dos demais artigos com semelhante característica, os autores localizam um problema próprio da sociedade contemporânea contra o qual se manifestam: nesse caso, o consumo massificado e a decorrente degradação dos ecossistemas. A prática do grupo por eles estudado procuraria se opor a essa tendência atual, sustentando, em oposição, princípios de consumo sustentável e agroecologia.

O que há aí de educação não escolar refere-se não a alguma proposta aplicável e previamente concebida para essa finalidade, mas sim à compreensão de uma iniciativa já em curso reputada como circunstância de educação ambiental. Essa compreensão se dá por uma conversão interpretativa: processos de consumo coletivo tornam-se processos de aprendizado coletivo; um grupo de compras coletivas torna-se uma comunidade aprendente; as trocas econômicas comerciais passam a equivaler a trocas de saberes.

Trata-se, assim, da atribuição de uma função educativa àquela prática, atribuição motivada pelo reconhecimento de um potencial pedagógico ali supostamente existente. No entanto, se considerarmos o caráter performativo do conhecimento - e, em nosso caso, do campo pedagógico -, a expansão de domínios de um saber ou disciplina deve ser pensada como também produtora de efeitos de realidade. Isso porque, segundo Foucault, o discurso engendraria os objetos sobre os quais se detém, não havendo "nenhuma semelhança, nenhuma afinidade prévia entre conhecimento e essas coisas que seria necessário conhecer" (FOUCAULT, 2008, p. 17).

Daí que a atribuição de estatuto pedagógico ou educativo a certos processos e práticas não se prestaria apenas a representá-los, mas a performá-los segundo uma nova condição. Nesse movimento, a prática estudada pelos autores do artigo passa a inscrever-se em determinado horizonte teórico, o que abre margem para que ela seja então, num momento posterior, alvo passível de intervenção pedagógica.

Cabe mencionar que o campo específico de teorização e intervenção que está em pauta nesse primeiro texto analisado é o da chamada pedagogia popular, estando os autores amparados no pensamento de Paulo Freire e em uma concepção crítica e emancipatória de educação, "entendida como o processo formal e não formal por meio do qual o sujeito apropria-se de sua cultura e constrói seus próprios sentidos e significados, podendo desenvolver sua autonomia de uma forma criativa e livre" (SANTOS; CHALUB-MARTINS, 2012, p. 477).

Se é possível reconhecer atributos educativos em determinada prática e sustentar um posicionamento propositivo perante tal reconhecimento, é também possível fazê-lo a partir de um 
endereçamento crítico. É o que vislumbramos, por exemplo, em um texto publicado na Revista Brasileira de Educação, intitulado Ensinando a dividir o mundo: as perversas lições de um programa de televisão (COSTA, 2002). O artigo contempla o eixo educação na extensão de espaços cotidianos, mais precisamente a categoria educação e mídia. Não por acaso, a escolha de uma abordagem crítica aqui deveu-se à grande ocorrência de textos com essa característica inclusos em tal tema.

O objetivo da autora foi analisar um programa televisivo diário voltado ao público infantil e adolescente. Para tanto, ela apresenta uma consideração geral sobre o que está em jogo no próprio aparato da televisão, definido como "o mais poderoso artefato cultural midiático da segunda metade do século XX” (COSTA, 2002, p. 74). Daí seu intento de analisar como determinada atração veiculada naquele meio repercutiria na educação do público a que se destina. Ou melhor: não se trata apenas de repercussão, como se a educação de fato estivesse fora do meio midiático e apenas fosse por ele influenciada; trata-se sim de uma operação intrinsecamente educacional ali levada a cabo.

Isso porque o artigo parte da compreensão de que a televisão seria "um dispositivo que integra o aparato pedagógico das sociedades governamentais modernas, ensinando muitas coisas" (COSTA, 2002, p. 71). Em relação ao programa então analisado, ele ensinaria a dividir o mundo conforme uma lógica binária orientada por definições identitárias propagandeadas pelos princípios neoliberais. Ao discutir os ensejos educacionais de seu alvo analítico, a autora põe em questão a "forma inconseqüente [sic] e despreocupada com que lidamos com as pedagogias culturais praticadas pela mídia" (COSTA, 2002, p. 71).

O teor crítico do texto mostra-se imediatamente evidente, mas é importante ressaltar que ele investe não apenas a educação praticada fora do ambiente escolar, como também aquilo que se opera dentro das escolas. É o que fica evidente no seguinte excerto: “Assim como a escola tem concentrado boa parte dessa tarefa [divisão binária neoliberal], do lado de fora dela e dos aparatos pedagógicos formais, institucionalizados, ensinam-se também muitas coisas que se encaixam inteiramente nessa lógica" (COSTA, 2002, p. 73). Tais ensinamentos estariam articulados no que a autora define como um currículo oculto, o qual não consistiria em um "um lugar maligno onde forças poderosas projetam nas sombras a subjugação de pobres sujeitos desprotegidos e incautos" (COSTA, 2002, p. 81) - esse que é justamente um dos polos da lógica binária que, segundo o artigo, orientaria o programa televisivo analisado. Antes, o que se propõe no referido texto é o esforço de evidenciar as forças envolvidas na produção contemporânea de determinados modos de vida - o que, não à toa, estaria em plena 
consonância com o pensamento de Michel Foucault, autor que serve de referência capital também àquela análise.

Mais uma vez, portanto, temos um artigo que reconhece operações de teor pedagógico em contextos não escolares. Em relação ao primeiro texto por nós abordado, é possível apontar, ainda, uma distinção relevante: se lá (SANTOS; CHALUB-MARTINS, 2012) havia abertura para o aprimoramento de uma intencionalidade pedagógica, aqui (COSTA, 2002) há justamente a crítica e a tentativa de desmonte de uma intencionalidade pedagogizante. Vejamos agora como se soma à discussão um texto que, em vez disso, apresenta a análise de uma prática não escolar designadamente concebida com finalidades pedagógicas.

Práticas corporais e velhice: uma relação possível (ANDRADE; MELO, 2008), publicado em Educação em Questão, insere-se no eixo que definimos como educação na extensão da vida e consiste na apresentação de uma intervenção pedagógica realizada com os residentes de uma instituição que abriga idosos carentes.

Partindo de uma contextualização da velhice em termos de suas modificações históricas, políticas públicas, dados estatísticos e interesse acadêmico-científico, os autores anunciam o problema que os mobiliza: a população idosa, sobretudo sua porção com menores recursos financeiros, embora cresça progressivamente, careceria de espaços e possibilidades efetivas para que a velhice fosse vivenciada de forma ativa. Daí a necessária atuação profissional a fim de garantir condições favoráveis a tal faixa etária.

A educação física foi o campo de atuação então convocado. Nas palavras dos profissionais envolvidos, a intervenção teve por objetivo "a construção e a vivência em práticas corporais que respeitassem os desejos, os limites e as possibilidades inerentes a cada velho envolvido nas atividades que coletivamente elaboramos e vivenciamos" (ANDRADE; MELO, 2008, p. 90). Assumia-se, assim, a premissa de que o cotidiano daqueles idosos estava atravessado pelo ócio, pelo sedentarismo e pela passividade, atributos considerados negativos para o exercício de uma velhice saudável.

A intervenção consistiu na proposição de práticas e jogos corporais aos idosos em um ambiente externo à instituição que habitavam. Sua preparação e sua execução foram permeadas por estratégias muito semelhantes àquelas encontradas em ações educacionais escolares direcionadas a crianças: era preciso envolver os idosos, convencê-los a participar das atividades, e, para tanto, eles foram convidados a colaborar para a confecção do material a ser utilizado (papel colorido, garrafas vazias, cabos de vassoura, balões etc.). Evidencia-se claramente, assim, o intento pedagógico na extensão dos 
tempos da vida: seja uma criança ou um velho o alvo de intervenção educacional, a lógica de atuação vê-se contornada por um caráter escolarizante similar.

E o que seria preciso aprender quando já se passou da idade para a qual se volta a educação escolar? Em diversos casos, trata-se de um acesso tardio aos mesmos conteúdos veiculados pela escola, quando tal acesso não se deu conforme esperado na faixa etária correspondente; em outros, de recorrer ao expediente escolar em nome de aprendizagens distintas daquelas. No contexto do artigo analisado, trata-se fundamentalmente de aprender uma nova relação com a própria fase da vida em que o sujeito se encontra - ou, poderíamos dizer, um outro modo de vida. Em síntese, trata-se de aprender a ser um novo velho, entendendo a velhice agora em termos de atividade, sociabilidade e autoconfiança. Não mais visto como aquele que enfim completou seu processo de aprendizagem, tal como se compreendia outrora, o idoso passa a ser ele próprio alvo direto de intervenções pedagógicas propiciadas pelos mais novos. Nesse sentido, não bastaria ter a experiência acumulada de uma vida; ao contrário, seria preciso aprender sempre; aprender a ser quem se é.

É oportuno assinalar, ainda, que o contexto tratado pelo artigo abrange circunstâncias alheias à relação de cada idoso com seu corpo ou com seu momento de vida: a situação da velhice na configuração social contemporânea brasileira, tal como anunciado pelos autores, diz respeito tanto a uma inversão gradual da pirâmide etária quanto a problemas de desigualdade social e de abandono familiar.

Nessa medida, pode-se dizer que a intervenção realizada procurou atuar num âmbito individualizado, tendo em vista questões que são essencialmente de cunho público e social. Não apontamos, com isso, nenhuma incoerência intrínseca, afinal, problemas de ordem socialmente mais ampla afetam sobremaneira vidas individuais, e é também nesse âmbito que o endereçamento a tais problemas pode ser pensado. No entanto, o que ressaltamos aqui é justamente o recurso a uma estratégia pedagógica como opção predominante, o que reafirma o lastro educacionalizante que vimos apontando em relação à abordagem de um conjunto de diferentes problemas sociais.

Se há iniciativas educacionais não escolares sendo desenvolvidas, seria preciso também haver um quadro profissional suficientemente qualificado para assumir a responsabilidade pelas atividades previstas. Eis que chegamos ao quarto e último eixo de nossa análise: formação e atuação profissional na educação não escolar. O texto selecionado a esse respeito foi O trabalho pedagógico nos processos educativos não-escolares [sic passim] (SÁ, 2000), publicado por Educar em Revista. 
A argumentação lança mão de um fator recorrente entre as justificativas para a educação não escolar: o processo de globalização e seus efeitos em termos de produção, economia, comunicação e desenvolvimento científico. Daí a emergência, segundo aponta o autor, de "novos atores e novos espaços privados de hegemonia no âmbito da sociedade civil que, contraditoriamente, reproduzem/produzem processos educativos de formação/deformação, de alienação/desalienação da cidadania" (SÁ, 2000, p. 173).

Efeito direto disso seria a concorrência da escola com outros espaços educativos na tarefa formativa. Por derivação de argumento, chega-se à proposição de que "a Pedagogia, ciência que estuda o fenômeno educativo escolar e não-escolar, passe a estudar e formar intelectuais, pedagogos para atuarem com competência epistêmico-política e técnica nestes novos cenários criados nas e pelas relações sociais" (SÁ, 2000, p. 173).

Ancorado na defesa de uma formação universitária específica para tais profissionais, o artigo traz à baila a necessidade de uma preocupação institucional, por parte do campo pedagógico, voltada aos processos educativos não escolares, evidenciando o que seria um movimento de formalização daquilo que, num primeiro momento, era tido como não formal. A relevância dessa ideia para os propósitos deste texto encontra-se no fato de que à educacionalização do espectro social corresponderia um processo de ampliação dos domínios de um campo com o fito de abarcar os novos objetos que ele passa a investir. Em outros termos, seria possível compreender o espraiamento do dispositivo pedagógico nos termos de uma objetivação performativa de novos e cambiantes domínios epistêmicos.

\section{O expansionismo pedagógico: considerações finais}

Na pretensão de construir um inventário do que tem se produzido a reboque de uma educação não escolar no contexto acadêmico brasileiro, foi-nos possível traçar algumas linhas de visibilidade a partir da cartografia que deu ensejo ao presente artigo. Assim, de modo geral, a expansão do intento pedagógico para além dos limites escolares afirma-se como um movimento crescente nos últimos 20 anos; sua manifestação desponta em produções tanto nacionais, quanto internacionais; há algumas concentrações temáticas do assunto entre as publicações periódicas e as instituições acadêmicas que sediam estudos nessa direção; a maior parte dos trabalhos manifesta-se, de algum modo, favorável a práticas educacionais não escolares; o alcance de aplicação de tais práticas abrange ao menos 22 regiões temáticas distintas e paralelas, as quais perfazem quatro grandes eixos de dispersão do intento educacionalizante - na extensão dos tempos da vida, na extensão dos espaços cotidianos, na extensão 
das questões socioculturais, na extensão das preocupações com a formação e a atuação do campo pedagógico não escolar.

Importa também ressaltar que a porção de textos identificada como crítica em relação ao suposto movimento de educacionalização não é desprezível, tendo sido inclusive superior ao que supúnhamos encontrar. Ao menos 23 (14\%) dos artigos selecionados manifestaram-se nessa direção, explicitando-se contrários a determinadas iniciativas - ou efeitos - educacionais não escolares, o que indica claramente a ausência de consenso a esse respeito no interior da comunidade acadêmica. De todo modo, a partir dos resultados encontrados foi possível vislumbrar que a educação, concebida em uma acepção genérica, tem contemplado práticas e teorizações aglutinadoras de diferentes demandas sociais - além de produzir outras tantas, num jogo permanente de performatividade e objetivação.

Em consonância com Marisa Vorraber Costa (2002, p. 80), autora de um dos artigos analisados, cumpre-nos ressaltar que consideramos que o "currículo da mídia", por exemplo, "não tem nenhum caráter impositivo. Chega-se a ele por interesse e deleite, e, pelo mesmo motivo, adere-se a ele". Algo semelhante ocorre com os demais temas tratados: sua defesa pode se dar por engajamento social, por resposta a problemas contemporâneos, por maior qualidade de vida, por defesa de direitos universais, e assim por diante. Não se trata aqui, em nenhum dos casos, de objetar aquilo que mobiliza tais iniciativas, tampouco de apontá-las como condições mandatórias ou conspiratórias aos modos de vida de nosso tempo. Entretanto, não é impunemente ou sem efeito que tais operações educacionais se forjam. E é na medida em que elas conformam modos específicos de governo e determinados processos de subjetivação que nos cabe interrogá-las.

Nesse sentido, um dos principais saldos analíticos da presente empreitada investigativa remete ao reconhecimento da existência de uma maquinaria educacional espraiada pelo espaço social, da qual a escola é certamente parte, mas não a única. Isso porque, se cidadão e aluno, em alguma instância, passam a ser condições subjetivas complementares dos indivíduos contemporâneos, não é exclusivamente na instituição escolar que essa associação vem sendo experienciada. Tal configuração, na visão de Roger Deacon e Ben Parker acerca da crescente permeabilidade das fronteiras entre as escolas, os contextos e os sujeitos, implicaria também "uma reformulação, até mesmo uma intensificação da produção da cidadania normalizada” (1998, p. 141). Assim, seria plausível admitir que, junto ao expansionismo pedagógico, haveria uma atualização produtiva de sujeitos-cidadãos intensamente pedagogizados. 
Por fim, parece-nos possível assumir que estaríamos a testemunhar uma dispersão das práticas educativas e um concomitante fortalecimento dos modos pedagogizantes - ou, em última instância, escolarizados - de modulação da experiência, dando margem a uma alunização radical dos sujeitos contemporâneos. Veem-se aí envolvidos temas, tempos e espaços renovados nos quais se alocam práticas de feições intencionalmente educativas, o que, se seguirmos a argumentação de Julia Varela (1999), talvez indique a irrupção de um modelo pedagógico singular, em termos históricos. Em seu trabalho, fundado em uma análise bastante distinta da historiografia tradicional, a autora expõe três tendências pelas quais a pedagogia ter-se-ia organizado historicamente - as pedagogias disciplinares, as corretivas e as psicológicas -, tendências estas caracterizadas por Varela (1999) de acordo com as concepções de espaço e tempo que nutriram cada uma delas. Se são as categorias espaço-temporais que, nessa perspectiva, informam modelos pedagógicos delimitados, não seria equivocado supor que, em um contexto de intensa valorização da experiência educativa não escolar, está-se forjando outro desenho e outra amplitude para o dispositivo educacional.

\section{REFERÊNCIAS}

AFONSO, A. J. A sociologia da educação e os contextos e processos educativos não-escolares. Educação \& Linguagem, v. 8, p. 35-44, 2003.

AQUINO, J. G. Disjunção, dispersão e dissensão da educação contemporânea. In: SARAIVA, K.; MARCELLO, F. A. (Orgs.). Estudos culturais e educação: desafios atuais. Canoas: Editora da ULBRA, 2012. p. 138-156.

BERNSTEIN, B. A pedagogização do conhecimento: estudos sobre recontextualização. Cadernos de Pesquisa, São Paulo, n. 120, p. 75-110, 2003.

COSTA, M. V. Ensinando a dividir o mundo: as perversas lições de um programa de televisão. Revista Brasileira de Educação, Rio de Janeiro, n. 20, maio/ago. 2002.

DEACON, R.; PARKER, B. Escolarização dos cidadãos ou civilização da sociedade? In: SILVA, L. H. (Org.). A escola cidadã no contexto da globalização. 2. ed. Petrópolis: Vozes, 1998. p. 138-153.

DEPAEPE, M. Between educationalization and appropriation: selected writings on the history of modern educational systems. Leuven: Leuven University Press, 2012.

FARGE, A. O sabor do arquivo. São Paulo: Edusp, 2009.

FOUCAULT, M. A verdade e as formas jurídicas. Rio de Janeiro: NAU, 2008. 
FOUCAULT, M. O governo de si e dos outros. São Paulo: Editora WMF Martins Fontes, 2010a.

FOUCAULT, M. O sujeito e o poder. In: DREYFUS, H.; RABINOW, P. Michel Foucault, uma trajetória filosófica: para além do estruturalismo e da hermenêutica. 2. ed. Rio de Janeiro: Forense Universitária, 2010b. p.273-295.

ANDRADE, J. P.; MELO, J. P. Práticas corporais e velhice: uma relação possível. Educação em Questão, Natal, v. 33, n. 19, p. 88-105, set./dez. 2008.

NOGUERA-RAMÍREZ, C. E. O governamento pedagógico: da sociedade do ensino para a sociedade da aprendizagem. 266f. 2009. Tese (Doutorado em Educação) - Universidade Federal do Rio Grande do Sul, Porto Alegre, 2009.

POPKEWITZ, T. S.; OLSSON, U.; PETERSSON, K. Sociedade da aprendizagem, cosmopolitismo, saúde pública e prevenção à criminalidade. Educação \& Realidade, Porto Alegre, v. 34, n. 2, p. 73-96, maio/ago. 2009.

SÁ, R. A. Pedagogia: identidade e formação. O trabalho pedagógico nos processos educativos nãoescolares. Educar em Revista, Curitiba, n. 16, p. 171-180, 2000.

SANTOS, F. P. S.; CHALUB-MARTINS, L. Agroecologia, consumo sustentável e aprendizado coletivo no Brasil. Educação e Pesquisa, São Paulo, v. 38, n. 2, p. 469-483, abr./jun. 2012.

VARELA, J. Categorias espaço-temporais e socialização escolar: do individualismo ao narcisismo. In: COSTA, M. V. (Org.). Escola básica na virada do século: cultura, política, currículo. São Paulo: Cortez, 1999, p. 73-106.

VIEIRA, E. A cidade e o governo dos homens: sobre o lastro educacional da urbanidade contemporânea. 98 f. 2012. Dissertação (Mestrado em Educação) - Faculdade de Educação, Universidade de São Paulo, São Paulo, 2012. 


\section{The educational foundations of contemporary experience: problematizations}

\begin{abstract}
In order to join the debate about what some authors have been calling pedagogization or educationalization of social issues, this paper proposes an approach to the discursive performativity around the intensification of educational practices beyond its formal version, understanding this movement as a social and historical process that has an undeniable impact on the management of human behavior and, by extension, on the formation of educable citizens. The analysis, whose theoretical and methodological foundations are inspired in the thought of Michel Foucault, undertakes a cartographic contextualization of theoretical and practical initiatives around out-of-school education based on a set of texts published in ten national newspapers of wide circulation in the area of education during the last two decades (1995-2014). Such empirical data, defined here as a locus of circulation and validation of what has been produced in the non-formal educational practices in recent times, offer special opportunity for a questioning of the new features the educational horizon has assumed. Therefore, the aim is to produce an inventory of thematizations, theories and methods that can be distinguished from the educational practices located outside the classical scope of school and, according to our hypothesis, that would carry a prominent educationalizating emphasis tending do permeate contemporary ways of life.
\end{abstract}

Keywords: Extra-school Education. Education journals. Foucault, Michel.

\section{Elisa Vieira}

E-mail: elisa.vieira@usp.br

\section{Julio Groppa Aquino}

E-mail: groppaq@usp.br

\section{Le base éducationnel de l'expérience contemporaine: problématisations}

\begin{abstract}
Résumé
À titre d'inscription dans le débat sur ce que certains auteurs désignent pédagogization ou éducacionalization du social, le présent article se propose à observer la performativité discursive autour de l'intensification des pratiques éducationnelles au-delà de sa version formelle, en comprenant ce mouvement comme un processus social et historique qui a un impact indéniable sur la gestion du comportement humain et, par extension, sur la conformation de citoyens éducables. L'analyse, dont le fondement théorique-méthodologique dialogue étroitement avec la pensée de Michel Foucault, entreprend une contextualisation cartographique des initiatives théoriques et pratiques qui sont autour de l'éducation non-formelle en prenant comme base un ensemble de textes publiés par dix journaux nationaux de grande diffusion dans le domaine de l'éducation pendant les deux dernières décennies (1995-2014). Tel matériel empirique, ici compris comme locus de circulation et validation de ce qu'on produit dans les pratiques pédagogiques nonformelles de ces derniers années, offre une occasion privilégiée pour la problématisation des nouvelles caractéristiques de l'actuel horizon éducationnel. Il s'agit, donc, de composer un inventaire de thématisations, théorisations et méthodes qui se déclarent associés aux pratiques éducationnelles qui sont situées hors de l'étendue classique de l'institution scolaire et qui, selon cette hypothèse, portent un important accent éducacionalizant pour l'investissement sur les modes contemporains de vie.
\end{abstract}

Mots-clés: Éducation Extra-Scolaire. Publications sur l'éducation. Foucault, Michel.

Enviado em: 10/5/2015

Aprovado em: 5/9/2016 